Characterizing high energy spectra of NIF ignition hohlraums using a differentially filtered high energy multi-pinhole X-ray imager

H. Park, E. D. Dewald, S. Glenzer, D. H. Kalantar, J. D. Kilkenny, B. J. MacGowan, B. R. Maddox, J. L. Milovich, R. R. Prasad, B. A. Remington, C. A. Thomas

May 18,2010

18th Topical Conference on High-Temperature Plasma Diagnostics Wildwood, NJ, United States May 16, 2010 through May 20, 2010 
This document was prepared as an account of work sponsored by an agency of the United States government. Neither the United States government nor Lawrence Livermore National Security, LLC, nor any of their employees makes any warranty, expressed or implied, or assumes any legal liability or responsibility for the accuracy, completeness, or usefulness of any information, apparatus, product, or process disclosed, or represents that its use would not infringe privately owned rights. Reference herein to any specific commercial product, process, or service by trade name, trademark, manufacturer, or otherwise does not necessarily constitute or imply its endorsement, recommendation, or favoring by the United States government or Lawrence Livermore National Security, LLC. The views and opinions of authors expressed herein do not necessarily state or reflect those of the United States government or Lawrence Livermore National Security, LLC, and shall not be used for advertising or product endorsement purposes. 


\title{
Characterizing high energy spectra of NIF ignition hohlraums using a differentially filtered high energy multi-pinhole X-ray imager ${ }^{a)}$
}

\author{
Hye-Sook Park, ${ }^{1, b)}$ E. D. Dewald, ${ }^{1}$ S. Glenzer, ${ }^{1}$ D. H. Kalantar, ${ }^{1}$ J. D. Kilkenny, ${ }^{1}$ B. \\ J. MacGowan, ${ }^{1}$ B. R. Maddox, ${ }^{1}$ J. L. Milovich, ${ }^{1}$ R. R. Prasad, ${ }^{1}$ B. A. Remington, ${ }^{1}$ \\ and C. A. Thomas ${ }^{1}$
}

${ }^{1}$ Lawrence Livermore National Laboratory, Livermore, California 94550, USA

(Presented XXXXX; received XXXXX; accepted XXXXX; published online XXXXX)

(Dates appearing here are provided by the Editorial Office)

\begin{abstract}
Understanding hot electron distributions generated inside hohlraums is important to the ignition campaign for controlling implosion symmetry and sources of preheat. While direct imaging of hot electrons is difficult, their spatial distribution and spectrum can be deduced by detecting high energy x-rays generated as they interact with the target materials. We used an array of 18 pinholes, with four independent filter combinations, to image entire hohlraums with a magnification of $0.87 \mathrm{x}$ during the hohlraum energetics campaign on NIF. Comparing our results with hohlraum simulations indicates that the characteristic $30 \mathrm{keV}$ hot electrons are mainly generated from backscattered laser plasma interactions rather than from hohlraum hydrodynamics.
\end{abstract}

\section{INTRODUCTION}

Hot electrons generated inside a hohlraum have been observed in many hohlraum experiments. Understanding their properties is important to the ignition campaign for controlling implosion symmetry and sources of preheat. ${ }^{1}$ Hot electron characteristics such as the energy distribution and total flux are typically inferred from hard x-ray measurements. Most hohlraum energetic campaign shots use the Filter Fluorescer (FFLEX) detector $^{2}$ which measures an absolute $\mathrm{x}$-flux from fluorescers excited by the high energy $\mathrm{x}$-rays produced from hot electron interactions with metal foils. This instrument is sensitive to all florescence $\mathrm{x}$-ray photons from the line of sight and gives no spatial information. During the hohlraum energetics campaign on NIF in 2009, we fielded a high energy $x$-ray imager with a large field-of-view. The imager had an array of 18 pinholes, with four independent filter combinations, to image entire hohlraums with a magnification of $0.87 x$. By analyzing the differentially filtered images, we were able to construct a spectrum of the hard x-rays emitted from different regions of the hohlraum.

\section{EXPERIMENTAL CONFIGURATION}

Figure 1 shows the experimental setup of the high energy multi-pinhole imager (HEMPI) system for a NIF ignition shot. The hohlraums, typically made of 30 to $50 \mu \mathrm{m}$ thick $\mathrm{Au}$, were placed at target chamber center (TCC) and the 192 beam lasers aligned to their laser entrance holes. During the 2009 campaign, up to $1.2 \mathrm{MJ}$ of laser energy were directed into the hohlraums. ${ }^{3,4}$ The self-emitting hohlraums were then imaged through the array of $18,100 \mu \mathrm{m}$ diameter pinholes. Since each hohlraum was fairly large (5.44 $\mathrm{mm}$ inner diameter and $10.1 \mathrm{~mm}$ long) a low magnification of $0.87 \mathrm{x}$ was achieved by placing the pinhole array $640 \mathrm{~mm}$ from TCC and the image plate $1198 \mathrm{~mm}$ from TCC. The

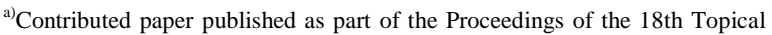
Conference on High-Temperature Plasma Diagnostics, Wildwood, New Jersey, May, 2010.

b) Author to whom correspondence: park1@1lnl.gov.

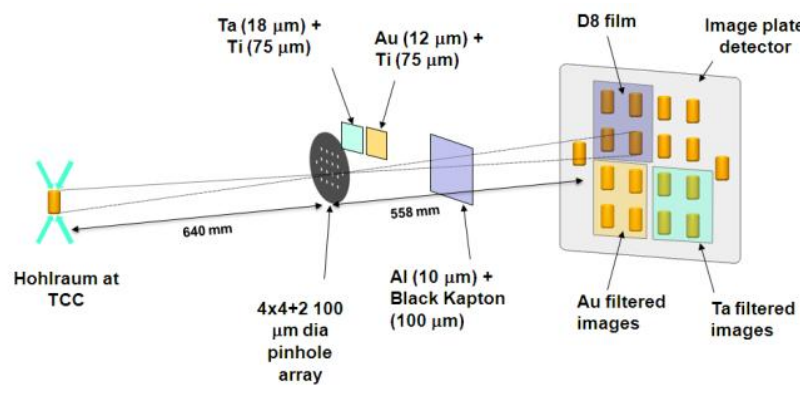

FIG. 1. (Color online). High Energy Multi-Pinhole Imager (HEMPI) configuration for a NIF ignition campaign shot. The multi pinhole array is divided into 4 different regions with 4 different $x$-ray filters.

pinhole array was divided into 4 regions each having different $\mathrm{x}$ ray filters between the pinholes and the image plate: Au+Ti $(12 / 75 \mu \mathrm{m}$ thick), Ta+Ti $(18 / 75 \mu \mathrm{m})$, a plastic Agfa D8 x-ray film, and a region of no filtering. All four regions were additionally filtered with $10 \mu \mathrm{m}$ of $\mathrm{Al}$ and $100 \mu \mathrm{m}$ of black kapton to shield the image plate from light. The Fuji SR-type image plates were previously absolutely calibrated using a high energy $x$-ray facility in Livermore 5 .

Hohlraum images recorded on the 1.0 MJ shot N091204001-999 are shown in Figure 2a. Because of the large size of the hohlraum, the images overlap slightly. Improved image quality was obtained by averaging the images with same filtering. Figure $2 b$ shows averages of the images filtered through the Au+Ti filter, left, and the images filtered through the plastic filter, right. The places where the inner and outer laser beams strike the hohlraum are clearly visible. The imploding capsule is visible in the rightmost image. 


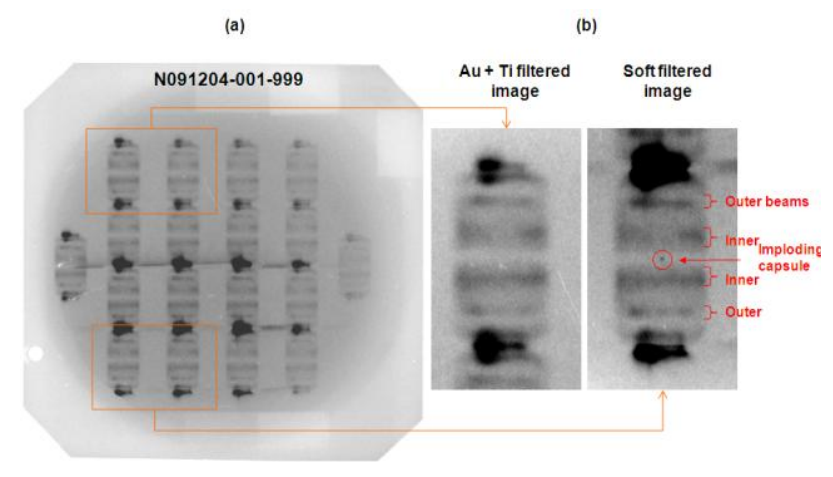

FIG. 2. (Color online). Images of the emitting hohlraum from shot N091204-001-999. The places where the inner and outer laser beams strike the hohlraum are clearly visible.

Of the 4 filters, the intensities in the images from the Au+Ti and $\mathrm{Ta}+\mathrm{Ti}$ filters were similar. Likewise were the images from the plastic and non-filtered region. Therefore in this analysis we only consider the images through the plastic and Au filters.

The total amount of $\mathrm{x}$-ray filtering is spatially dependent because of the complex thermal mechanical package attached to the hohlraum for these cryogenic shots. Figure 3 shows the the hohlraum build-up for shot N091204-001-999 showing various thicknesses of $\mathrm{Au}$ and $\mathrm{Al}$ in different regions of the hohlraum. The detailed components are listed in the figure along with the views from the detector angle and the laser illumination pattern. For the analysis, all these different materials and their thicknesses were considered.

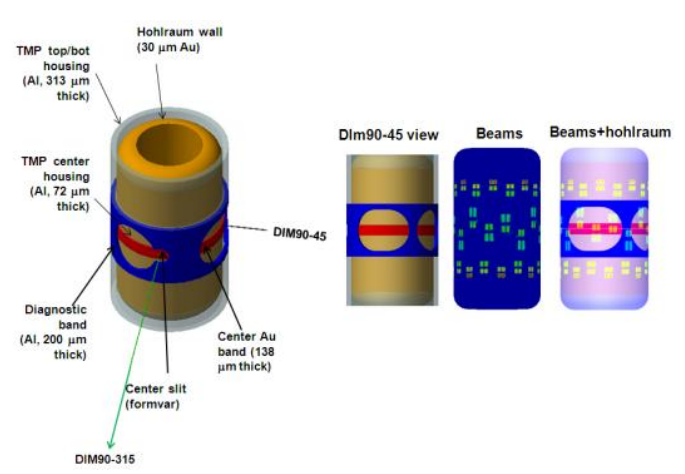

FIG. 3. (Color online). Schematic of scale 1.07 hohlraum showing the components of the cryogenic package and diagnostics views. The materials and thicknesses along the detector line-of-sight were considered in the analysis of the HEMPI images.

\section{.III. DATA ANALYSIS AND DISCUSSION}

The analysis proceeds by measuring the ratio of the flux through the plastic filter to the flux through the gold filter in different regions of the image. Fig 4 shows lineouts through the averaged images after subtracting a background level deduced from adjacent, dark areas. The blue-solid line is from the plastic filtered image and the black-dotted line is from the $\mathrm{Au}$ filtered image. The central capsule area also shows a difference between these 2 images. From these lineouts, we derive the image

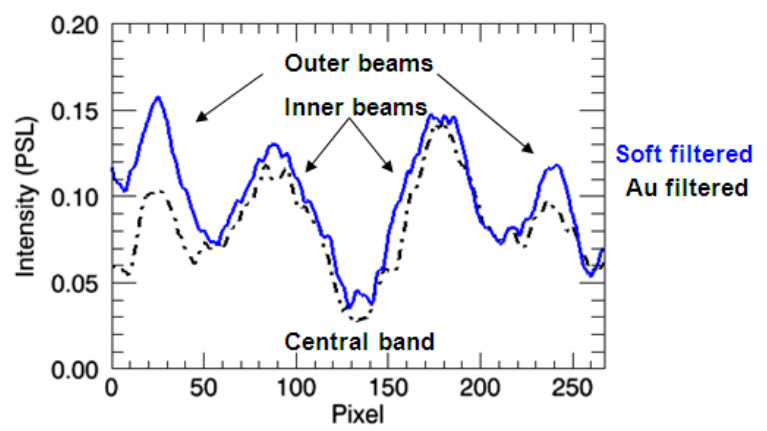

FIG. 4. (Color online). Background subtracted lineouts of the average image intensity along the hohlraum axis.

TABLE I. Image intensity ratios from different regions of the hohlraum. Note that the different regions go through different materials and different thicknesses.

\begin{tabular}{|c|c|c|}
\hline Ratio Regions & $\begin{array}{l}\text { Image } \\
\text { intensity } \\
\text { ratio }\end{array}$ & Filter Material \\
\hline $\begin{array}{l}\text { Outer beam area } \\
(\mathrm{Soft} / \mathrm{Au})\end{array}$ & $1.35 \pm 0.14$ & $\begin{array}{l}\text { Film/(Au+Ti) + TMP } \\
313 \mu \mathrm{m} \mathrm{Al}+\text { Hohl wall } \\
30 \mu \mathrm{m} \mathrm{Au}\end{array}$ \\
\hline $\begin{array}{l}\text { Inner beam area } \\
\quad(\mathrm{Soft} / \mathrm{Au})\end{array}$ & $1.15 \pm 0.11$ & $\begin{array}{c}\text { Film/(Au+Ti) + TMP } 72 \\
\mu \mathrm{m} \mathrm{Al}+\text { Hohl wall } 30 \\
\mu \mathrm{m} \mathrm{Au}\end{array}$ \\
\hline $\begin{array}{c}\text { Central band/outer } \\
(\mathrm{Au})\end{array}$ & $3.9 \pm 0.4$ & $\begin{array}{c}\{(\mathrm{Au}+\mathrm{Ti})+\mathrm{TMP} 313 \\
\mu \mathrm{m} \mathrm{Al}+\mathrm{Hohl} \text { wall } 30 \\
\mu \mathrm{m} \mathrm{Au}\} /\{(\mathrm{Au}+\mathrm{Ti})+ \\
\text { TMP } 313 \mu \mathrm{m} \mathrm{Al}+\mathrm{Hohl} \\
\text { center } 138 \mu \mathrm{m} \mathrm{Au}\}\end{array}$ \\
\hline $\begin{array}{l}\text { Capsule } \\
\text { (Soft/Au) }\end{array}$ & $2.0 \pm 0.2$ & Film/(Au+Ti) \\
\hline
\end{tabular}

intensity ratios listed in Table 1 for 4 regions of the images. The errors are dominated by photon statistics.

In order to interpret these ratios, we assume the hard x-rays are generated by bremsstrahlung in the hohlraum walls. Then, the functional form of the $\mathrm{x}$-ray spectrum will be:

$$
F(E, T) \approx F_{0} \exp (-E / k T)
$$

where $F_{0}$ is a constant, $E$ is the x-ray energy, $k$ is the boltzman constant, and $T$ is the characteristic temperature of the source. Using this spectrum we calculate the image plate detector response as:

$$
I_{I P}=\int F(E, T) \cdot T_{\text {hohl }}(E) \cdot T_{\text {filter }}(E) \cdot R_{\text {Detector }}(E) d E \cdot \Omega
$$

where $T_{h o h l}(E)$ is the transmission through the hohlraum materials, $T_{\text {filter }}(E)$ is the transmission through the filter materials, $R_{\text {Detector }}(E)$ is image plate response function and $\Omega$ is the detector pixel solid angle. 
We now fit a characteristic temperature that produces the image ratios seen by our data according to the bremsstrahlung spectra given above. The solid line in Figure 5 shows the expected image intensity ratio vs. temperature for the Outer beam area of the hohlraum body. (The corresponding line for the Inner beam area is similar as the Inner beam area has only an additional 150 microns of $\mathrm{Al}$ filtering.) From this plot, the measured ratio of 1.15 and 1.35 for the outer and inner beam areas correspond to temperatures of $40 \mathrm{keV}$ and $10 \mathrm{keV}$ respectively. There is no physics basis stipulating that the characteristic temperature is uniform inside the hohlraum, This imaging system uniquely provides spatially distinguishable temperature distribution.

The central hohlraum area had an additional $138 \mu \mathrm{m}$ thick

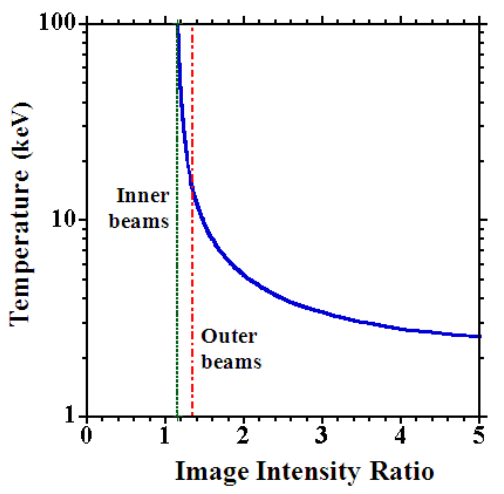

FIG. 5. (Color online). Image ratio vs the characteristic Maxwellian temperatures. Our data is best fitted with $40 \mathrm{keV}$ for the inner beam area and $10 \mathrm{keV}$ for the outer beam areas.

$\mathrm{Au}$ band and showed no difference between the plastic filtered and $\mathrm{Au}$ filtered images. Therefore, we considered the ratios within the Au filtered image between the central band area and the outer beam areas where the measure ratio was $3.9 \pm 0.4$ and conclude that the characteristic temperature in this region is 22 $\mathrm{keV}$.

The capsule showed the most distinct difference: i.e. the 12 $\mu \mathrm{m}$ thick Au filter blocked its transmission completely. The capsule is held by a thin formvar and the central $20 \mu \mathrm{m}$ of the hohlraum is cut out to place this layer. Assuming we are seeing the capsule through this small opening, and with a measured image intensity ratio of $>4$, we can set an upper limit to the electron temperature of the capsule of $<25 \mathrm{keV}$.

\section{CONCLUSION}

The details of the temperature production mechanism are still under investigation. Initial 3-D Hydra simulation indicates that the laser spot plasma generated on the hohlraum wall can produce hot electrons but not at the flux levels seen in this data. The FFLEX temperature measurement for this shot was consistent with the numbers presented in this paper.

We have shown that the multi-pinhole imager can be used to study spatially resolved high energy emission from a laser driven hohlraum through differential filtering. This first set of experiments in 2009 showed that the characteristic temperature is on the order of $30 \mathrm{keV}$, much higher than the temperature expected from pure hohlraum hydro dynamics. Detailed 3-D simulations of the hohlraums from these experiments are continuing. A possible mechanism under consideration is hot electrons generated from laser-plasma scattering instabilities via stimulated Raman scattering. ${ }^{6}$ Two other shots (N091205-001999 and N091124-001-999) from this campaign show similar 10 's of keV temperatures. We are now constructing a pinhole array with more varied material types and thicknesses to further constrain the source spectrum and brightness.

\section{ACKNOWLEDGEMENTS}

This work was performed under the auspices of the U.S. Department of Energy by the Lawrence Livermore National Laboratory under Contract No. DE-AC52-07NA27344.

\section{REFERENCES}

${ }^{1}$ J.D. Lindl, P. Amendt, R. L Berger, S. G. Glendinning, S.H. Glenzer, S.W. Haan, R.L. Kauffman, O.L.Landen, Phys. Plasmas 11, 339 (2004).

${ }^{2}$ E.L. Dewald, L.J. Suter, C. Thomas, S. Hunter, D. Meeker, N. Meezan, S.H. Glenzer, E. Bond, J. Kline, S. Dixit,, R.L Kauffman, J. Kilkenny, and O.L. Landen, IFSA conference proceedings, submitted (2010).

${ }^{3}$ N. B. Meezan, L. J. Atherton, D. A. Callahan, E. L. Dewald, S. Dixit, E. G. Dzenitis, M. J. Edwards, C. A. Haynam, D. E. Hinkel, O. S. Jones, O. Landen, R. A. London, P. A. Michel, J. D. Moody, J. L. Milovich, M. B. Schneider, C. A. Thomas, R. P. J. Town, A. L. Warrick, S. V. Weber, K. Widmann, S. H. Glenzer, L. J. Suter, B. J. MacGowan, J. L. Kline, G. A. Kyrala, and A. Nikroo, Phys. Plasmas 17, 056304 (2010).

${ }^{4}$ S. H. Glenzer, B. J. MacGowan, P. Michel, N. B. Meezan, L. J. Suter, S. N. Dixit, J. L. Kline, G. A. Kyrala, D. K. Bradley, D. A. Callahan, E. L. Dewald, L. Divol, E. Dzenitis, M. J. Edwards, A. V. Hamza, C. A. Haynam, D. E. Hinkel, D. H. Kalantar, J. D. Kilkenny, O. L. Landen, J. D. Lindl, S. LePape, J. D. Moody, A. Nikroo, T. Parham, M. B. Schneider, R. P. J. Town, P. Wegner, K. Widmann, P. Whitman, B. K. F. Young, B. Van Wonterghem, L. J. Atherton, E. I. Moses, Science 327,1228 (2010).

${ }^{5}$ B. R. Maddox,, H. -S. Park, B. A. Remington, N. Izumi, S. Chen, C. Chen, G. Kimminau, Z. A. Ali, M. J. Haugh, and Q. Ma, Review of Sci In., submitted (2010).

${ }^{6} \mathrm{~W}$. Kruer, Physics of Laser Plasma Interactions, Addison-Wesley Publishing Co. (1988). 